\title{
Intrathecal Synthesis of Autoantibodies to Myelin Basic Protein in Multiple Sclerosis
}

\author{
Ingrid Catz and Kenneth G. Warren
}

\begin{abstract}
A solid phase radioimmunoassay was used to detect anti-myelin basic protein (MBP) antibodies in the CSF and serum of multiple sclerosis (MS) patients and controls. CSF and serum samples were assayed prior to acid hydrolysis in order to detect free anti-MBP as well as after acid hydrolysis to measure the total (free and bound) amount of antibody. An anti-MBP index controlling for serum levels as well as the degree of breakdown of the blood brain barrier was used to estimate intrathecal synthesis of anti-MBP. MS patients with acute exacerbations or chronically progressive disease have significantly elevated levels of both free and total CSF anti-MBP. The anti-MBP index is also significantly increased in MS patients with both forms of active disease. Anti-MBP antibodies are intrathecally produced in MS patients with active disease.
\end{abstract}

RÉSUMÉ: La synthèse intrathécale des anticorps à la protéine basale de la myéline dans la sclérose en plaques Nous avons employé une radio-immuno-essai en phase solide (RIA) pour mesurer les anticorps anti-protéine basale de la myéline (MBP) dans le LCR et le sérum des patients avec sclérose en plaques (SEP) et de témoins. Les échantillons de sérum et de LCR furent dosés avant hydrolyse acide pour mesurer les anti-MBP libres et après hydrolyse acide pour mesurer les anticorps totaux (libres et liés). Nous avons utilisé un index anti-MBP, qui tenait compte des niveaux sériques et du degré de désintégration de la barrière hémo-encéphalique, pour mesurer la synthèse intrathécale des anti-MBP. Les patients avec SEP en poussée aiguë ou avec une forme progressive chronique montraient des niveaux élevés d'anti-MBP libres et totaux dans le LCR. L'index anti-MBP est également significativement plus élevé chez les patients SEP avec les deux formes de maladie active. Il est conclu que les anticorps anti-MBP sont produits de façon intrathécale chez les patients avec SEP en phase active.

Can. J. Neurol. Sci. 1986; 13:21-24

Multiple sclerosis (MS) is an acquired demyelinating disease of the central nervous system (CNS). The myelin sheath of the CNS is produced by oligodendrocytes. Myelin basic protein (MBP), a component of the myelin sheath, may be an important autoimmunogen in MS since it is capable of inducing experimental allergic encephalomyelitis, an animal model of MS.' In MS patients with active disease, the cerebrospinal fluid (CSF) MBP is elevated, potentially serving as a chronic and recurrent autoimmunizing stimulus. ${ }^{2,3,4}$

Another feature of MS is increased IgG synthesis within the blood brain barrier (BBB) ${ }^{5-9}$ CSF IgG or IgG eluted from brain tissue of MS patients is characterized by oligoclonal bands superimposed on a background of polyclonal IgG. ${ }^{10-13}$ Oligoclonal banding is indicative of intrathecal IgG synthesis and it occurs in most MS patients. Whether they have active or inactive disease, the majority of clinically definite MS patients have increased intrathecal IgG synthesis. ${ }^{9}$ Theoretically, some of the IgG may be protective, while some may be involved in the pathogenesis of demyelination. The specificity of the majority of intrathecally produced $\mathrm{IgG}$ has not been elucidated. ${ }^{14,15}$

The recent observation of Dasgupta $\mathrm{et} \mathrm{al}^{16}$ of MBP containing immune complexes in the blood of some MS patients led us to examine whether antibodies to MBP (anti-MBP) are intrathecally produced and whether their production is associated with disease activity. 


\section{METHODS}

Anti-MBP levels were determined in CSF and serum before and after acid hydrolysis by a solid phase radioimmunoassay. ${ }^{17}$ The final IgG concentration in all CSF and serum samples was adjusted to $0.010 \mathrm{~g} / \mathrm{L}$. Immulon microtiter plates ( 96 wells/plate) were coated with human MBP (hMBP concentration $=1.0$ ug/well). Staphyloccocus A Protein (Staph A Prot) was iodinated $\left(\mathrm{I}^{125}\right)$ by the method of Hunter and Greenwood. ${ }^{18}$ Aliquots of $100 \mathrm{ul} \mathrm{CSF}$ or serum $(\mathrm{IgG}$ concentration $=0.010 \mathrm{~g} / \mathrm{L}$ ) before and after acid hydrolysis were incubated in MBP coated wells for 2 hours at room temperature. After 5 washes, goat antihuman immunoglobulin was added and incubation continued for 1 hour at room temperature. After another 5 washes $I^{125}-$ Staph A Prot $(50,000 \mathrm{cpm} /$ well $)$ was added and the plates were incubated overnight at room temperature and finally, after 5 more washes the wells were individually counted. Results were expressed as percent (\%) bound of total radioactivity (TC). Two positive (serum from a rabbit immunized with hMBP and a positive CSF pool) and two negative controls were used in each assay. When CSF samples with initially high IgG and anti-MBP values were serially diluted the anti-MBP levels (\% bound) were parallel to the IgG concentrations. This assay was also validated by absorbing CSF anti-MBP with MBP prior to performing the assay. Absorbtion to MBP resulted in complete elimination of anti-MBP from samples that initially had high anti-MBP titers. Intraassay variability (CV) for 25 sets of duplicates was 3.86, while interassay variability (CV) for one set of quadruplicates over 10 different runs was 7.75 . In order to determine nonspecific adherence of $\mathrm{IgG}$ to immulon plates, each sample was also assayed in wells that were not coated with hMBP. This nonspecific binding ( $\leqslant 1 \%$ of $\mathrm{TC}$ ) was subtracted from the matched counts of CSF and serum samples.

Anti-MBP levels were determined in $74 \mathrm{MS}$ and 88 control patients. All MS patients had clinically definite disease. ${ }^{19}$ This group consisted of 15 patients in clinical remission with inactive disease (R) and 59 with active disease of which 31 had acute exacerbations (E) and 28 were experiencing chronically progressive MS (P). The control group consisted of 25 neurologically normal patients with psychoneurosis $(\mathrm{N}), 32$ with degenerative disc disease (M) and 31 with various neurological diseases exclusive of MS.

Anti-MBP levels before and after acid hydrolysis in CSF and serum were expressed for each of the above clinical groups as $\%$ bound radioactivity $\pm 2 \mathrm{SD}$. Intergroup statistical differences were performed by Student's t test. Intrathecal anti-MBP synthesis was calculated by the anti-MBP index:

\section{Anti-MBP Index $=\quad$ CSF/Serum anti-MBP $1000(\mathrm{CSF} /$ Serum Albumin $)$}

This index was determined on the basis of post acid hydrolysis values. In this formula, the serum anti-MBP level controls for the amount of antibody present in the serum and the CSF/Serum albumin ratio controls for the degree of breakdown of the blood brain barrier which permits increased leakage into the CSF. Intergroup differences of anti-MBP indexes were again determined by Student's $t$ test.

\section{RESULTS}

All results are expressed as $\%$ bound radioactivity $\pm 2 S D$. Nonspecific binding of IgG to immulon wells that were not coated with hMBP was subtracted from each sample value.

Results in 88 control patients were $2.3 \pm 0.5$ in CSF with a corresponding serum value of $0.8 \pm 0.6$. Patients with psychoneurosis and degenerative disc disease had similar low values in both $\operatorname{CSF}(1.5$ to $1.7 \pm 0.4)$ and serum $(0.7 \pm 0.5)$. This was due to nonspecific binding of immunoglobulins to MBP, and do not represent anti-MBP. These values were considered normal. The control neurological disease group had slightly higher CSF $(3.8 \pm 0.6)$ and serum $(1.1 \pm 0.6)$ results. While the majority of these patients with neurological diseases exclusive of MS had values similar to those of patients with psychoneurosis, a patient with subacute sclerosing panencephalitis (SSPE) and two of eight patients with post infectious encephelomyelitis (PIE) had higher results. The patient with SSPE had 16.0 in CSF and 3.9 in serum and the patients with PIE had 3.1 and 3.0 in CSF and 1.2 and 1.0 in serum. These CSF values were significantly increased and represent anti-MBP activity.

Anti-MBP was detectable in significantly higher amounts in CSF and serum of patients with active disease as opposed to those in remission or a group of controls (Table 1, Figure 1). In all MS clinical subgroups except patients in remission, post acid hydrolysis levels were higher than prehydrolysis values. Data was analyzed on the basis of total anti-MBP levels obtained after acid hydrolysis.

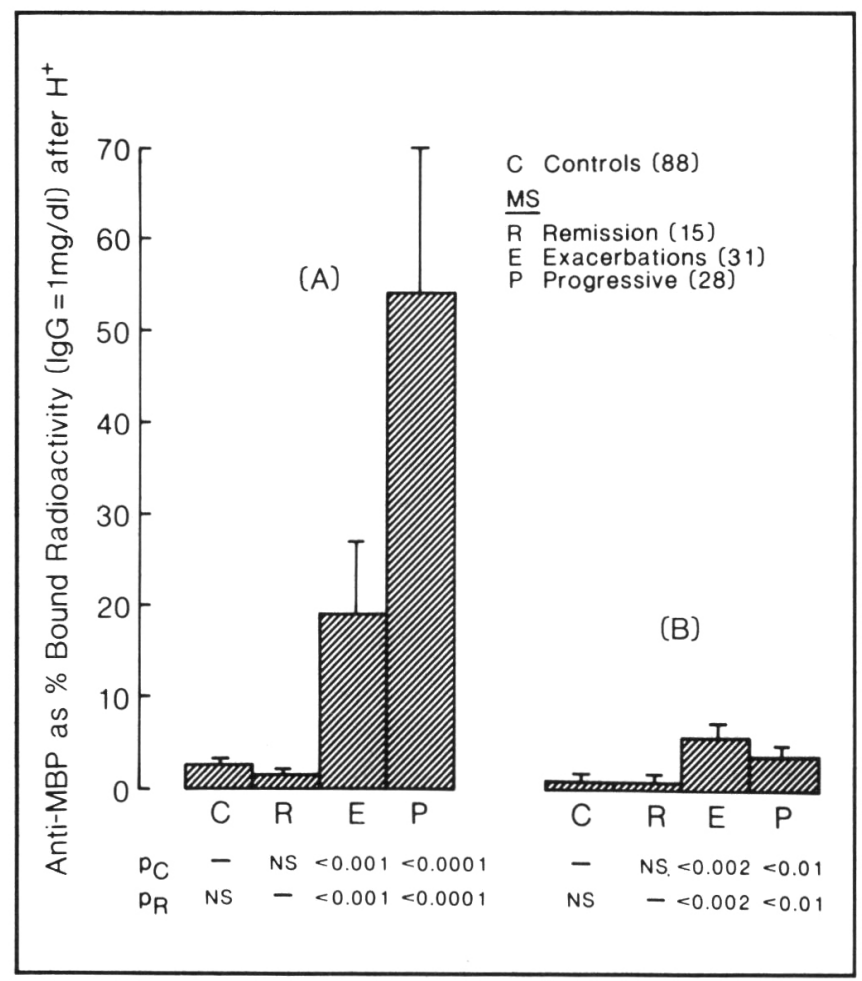

Figure I - Anti-MBP levels (mean $\pm 2 S D$ ) in CSF (A) and serum (B) of multiple sclerosis $(M S)$ and control $(C)$ patients.

$P_{C}$ : Student's t test versus control patients

$P_{R}:$ Student's test versus MS patients in remission 
Table 1: Anti-MBP Index and the effect of acid hydrolysis on anti-MBP levels in CSF and serum of multiple sclerosis (MS) patients and controls.

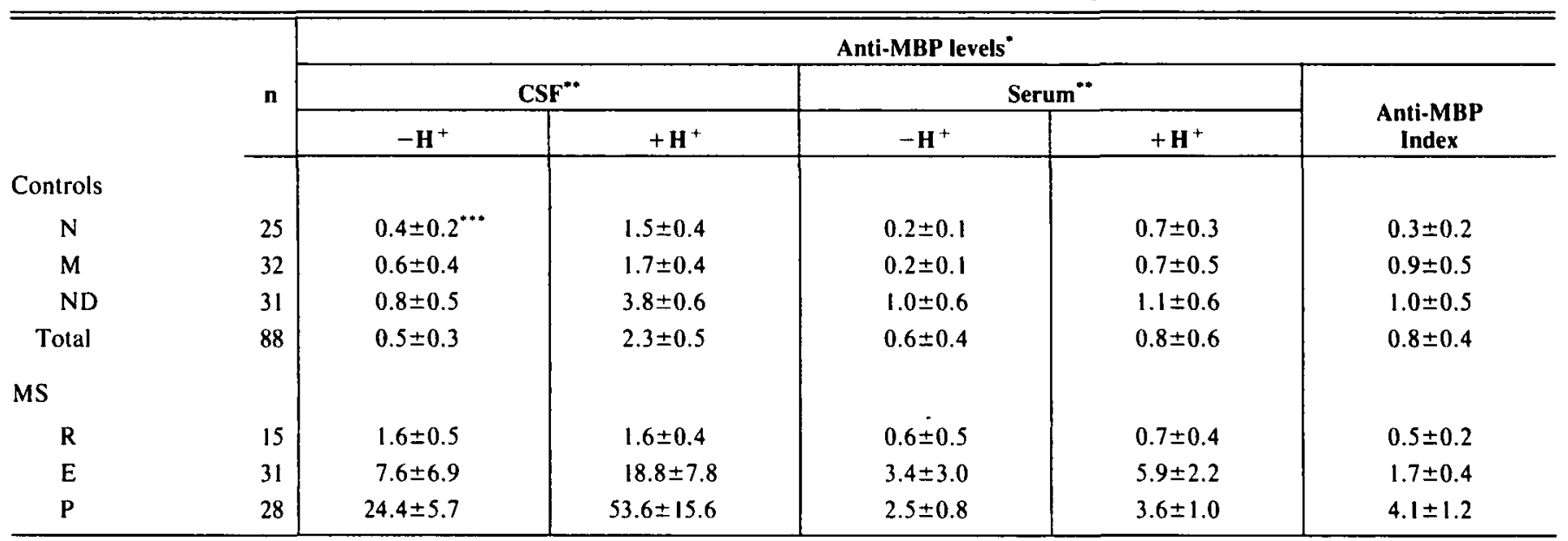

$\therefore:$ Anti-MBP levels expressed as $\%$ bound radioactivity
$\therefore$ : CSF and serum samples assayed at $0.01 \mathrm{~g} / \mathrm{L} \mathrm{lgG}$

$*$ : Results expressed as mean $\pm 2 \mathrm{SD}$

Anti-MBP Index $=\frac{\text { CSF/serum anti-MBP }}{1000(\mathrm{CSF} / \text { serum albumin })}$

Patients subgroups:

CONTROLS:

$\mathrm{N}=$ psychoneurosis
$\mathrm{M}=$ degenerative disc disease
$\mathrm{ND}=$ neurological diseases
MS:

$R=$ remission
$E=$ exacerbation
$P=$ progressive

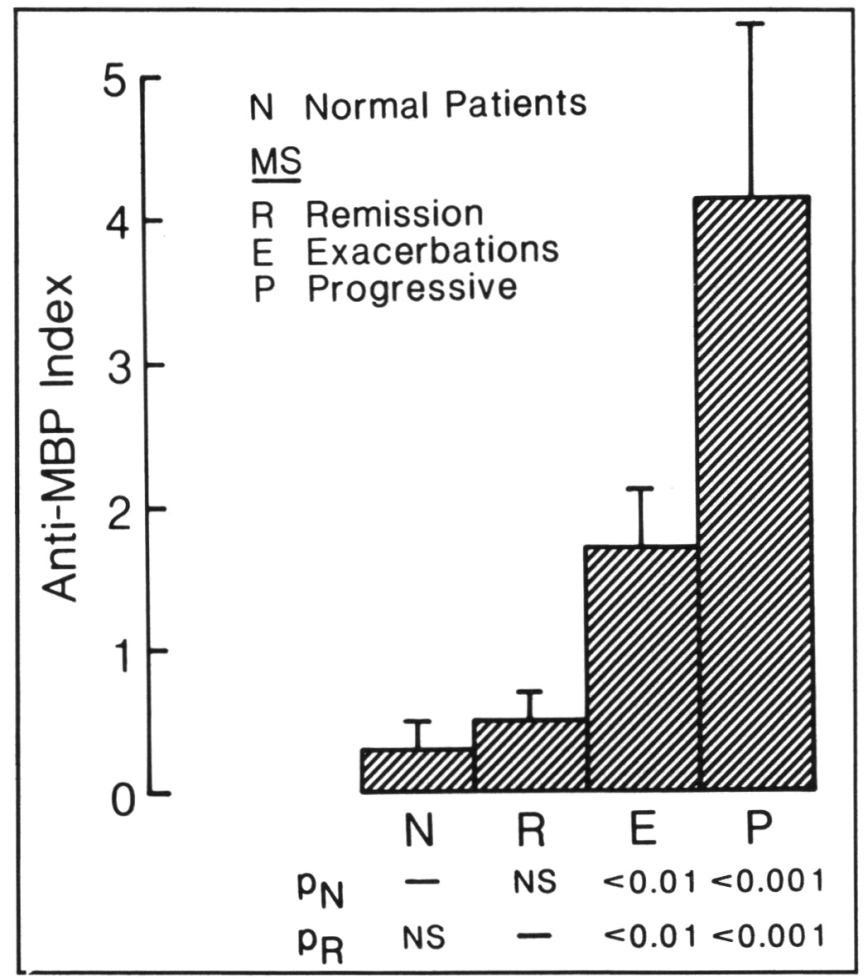

Figure $2-$ Anti-MBP Index (mean $\pm 2 S D$ ) in multiple sclerosis and normal patients.

$P_{N}:$ Student's t test versus normal patients

$P_{R}$ : Student's t test versus patients in remission
Although MS patients in remission had increased levels of intrathecal IgG synthesis, their anti-MBP value was not detectable in either CSF $(1.6 \pm 0.4)$ or serum $(0.7 \pm 0.4)$. In contrast, MS patients with active disease had increased levels. Patients experiencing acute exacerbations had significantly elevated levels in both CSF (18.8 \pm 7.8$)$ and serum $(5.9 \pm 2.2)$. The highest CSF levels $(53.6 \pm 15.6)$ were observed in MS patients with chronically progressive disease. Their serum level $(3.6 \pm 1.0)$ was lower than patients with acute exacerbations. CSF and serum anti-MBP levels were significantly higher in MS patients with active disease versus MS patients in remission or control patients (Figure 1).

In the normal (N) control group, the anti-MBP index was $0.3 \pm 0.2$ (Table 1, Figure 2). The index was not significantly elevated in MS patients in remission. Similar to anti-MBP levels, all MS patients with active disease had significantly higher anti-MBP indexes. The highest values were found in patients with chronic progressive disease $(4.1 \pm 1.2)$. The index was $1.7 \pm 0.4$ in patients with exacerbations.

\section{Discussion}

Intrathecal IgG synthesis is a hallmark of MS. ${ }^{5.9}$ Although intrathecal IgG synthesis is increased in the majority of MS patients whether they have active or inactive disease, it was not the purpose of this study to determine the amount of total CSF IgG with specificity for MBP. It has been suggested that some of the intrathecal IgG is "nonsense antibody" without significance for MS. ${ }^{14}$ On the other hand, Panitch et $\mathrm{al}^{20}$ using a radioimmunoassay with guinea pig MBP, reported low anti- 
MBP levels in MS patients with exacerbations. While several other authors have found antibodies against MBP in MS CSF, ${ }^{21,22}$ there have also been reported negative results. ${ }^{17}$ In this report we have demonstrated that autoantibodies to MBP are intrathecally produced in MS patients with active disease and that their presence correlates with disease activity. Conversely, anti-MBP was not present in MS patients in remission. Highest levels detected in patients with chronic progressive disease may be due to prolonged release of MBP into their CSF and serum and to the spatial dissemination of the pathology within the CNS. Longitudinal case studies of patients with chronic progressive disease from our Multiple Sclerosis Patient Care and Research Clinic have shown CSF anti-MBP consistently present in high titers. Clinically active MS whether in the form of acute exacerbations or chronic progressive disease is characterized by the presence of both free circulating and bound anti-MBP antibodies.

Analysis of the CSF prior to acid hydrolysis detected free antibody in most patients with both forms of clinically active disease. However, the relative quantities of free and bound anti-MBP in different MS clinical subgroups has yet to be determined. Increased anti-MBP post hydrolysis values indicate that this antibody may be bound to proteins such as MBP or anti-idiotypes.

Intrathecally synthesized IgG which does not have specificity for MBP may be directed against other oligodendrocyte or myelin proteins, ${ }^{22,23,24}$ viral antigens, ${ }^{25,26}$ or they may have a protective role as anti-idiotypic antibodies ${ }^{27,28}$ or be involved in immunoregulation.

Although anti-MBPantibodies may be increased in neurological diseases other than MS, such as SSPE and PIE, this does not negate the possibility that they may play a role in the pathogenesis of this disease. Whereas diseases other than MS with elevated anti-MBP may be associated with normal immunoregulation of the antibody, MS may be due to altered regulation of anti-MBP. Analyses of CSF from MS patients should include assays to detect MBP and anti-MBP as well as estimates of intrathecal IgG synthesis and oligoclonal banding.

\section{ACKNOWLEDGEMENTS}

This research was supported in part by the Multiple Sclerosis Society of Canada (Alberta Division), the Friends of the University of Alberta Multiple Sclerosis Research Clinic, the Tegler Foundation of Edmonton, Alberta, Canada and a special contribution from Ms. Gertrude Gerth and friends of Barrhead, Alberta, Canada. Dr. D. Carroll, Ms. D. Olmstead, Ms. J. Christopherson, Ms. P. Shaw and Ms. B.L. Morris assisted with the clinical care of patients with progressive disease and Ms. V. Jeffrey provided excellent technical support. We are grateful for the support and encouragement of Dr. Harold Jacobs during the performance of this research.

\section{REFERENCES}

1. Rivers TM, Sprunt DH, Berry GP. Observations on attempts to produce acute disseminated encephalomyelitis in monkeys. J Exp Med 1933; 58: 39-53.

2. Cohen SR, Brooks BR, Herndon RM, McKhann GM. A diagnostic index of active demyelination: Myelin basic protein in cerebrospinal fluid. Ann Neurol 1980; 8: 25-31.

3. Whittaker JN, Lisak RP, Bashir RM et al. Immunoreactive myelin basic protein in the cerebrospinal fluid in neurological diseases. Ann Neurol 1980; 7: 58-64.

4. Warren KG, Catz I, McPherson TA. CSF myelin basic protein levels in acute optic neuritis and multiple sclerosis. Can J Neurol Sci 1983; 10: 235-238.
5. Kabat EA, Glusman M, and Knaub V. Quantitative estimation of the albumin and gamma globulin in normal and pathologic cerebrospinal fluid by immunochemical methods. Ann J Med 1948; 4: 653-662.

6. Tourtellotte WW. On cerebrospinal fluid IgG quotients in multiple sclerosis and other diseases. A review and new formula to estimate the amount of IgG synthesized per day by the central nervous system. J Neurol Sci 1970; 10: 279-304.

7. Link $\mathrm{H}$, Tibbling G. Principles of albumin and IgG analyses in neurological disorders. II. Evaluation of IgG synthesis within the central nervous system in multiple sclerosis. Scand J Clin Lab Invest 1977; 37: 397-401.

8. Tourtellotte WW, Ma BI. Multiple sclerosis: The blood brain barrier and the measurement of de novo central nervous system IgG synthesis. Neurology 1978; 28: 76-83.

9. Warren KG, Catz I. An investigation of the relationship between cerebrospinal fluid myelin basic protein levels and IgG measurements in multiple sclerosis patients. Ann Neurol 1985; 17:475-480.

10. Delmotte P. Gel isoelectric focusing of CSF proteins: A potential diagnostic test. Z Klin Chem Biochem 1971; 9: 334-336.

11. Link H. Oligoclonal IgG in MS brain. J Neurosci 1972; 16: 103-114.

12. Johnson KP, Nelson BJ. Multiple sclerosis: diagnostic usefulness of cerebrospinal fluid. Ann Neurol 1977; 2: 425-431.

13. Gilden D, Tachovsky T. Immunoglobulin elution from multiple sclerosis brain. J Neurosci Methods 1979; 1: 133-142.

14. Mattson DH, Roos RP, Amason BJW. IEF of IgG eluted from MS and SSPE brains. Nature 1980; 287: 335-337.

15. Mattson DH, Roos RP, Arnason BJW. Oligoclonal IgG in multiple sclerosis and subacute sclerosing panencephalitis. J Neuroimmunol 1982; 2: 261-276.

16. Dasgupta MK, Catz I, Warren KG, McPherson TA, Dossetor JB, Carnegie PR. Myelin basic protein: A component of circulating immune complexes in multiple sclerosis. Can J Neurol Sci 1983; 10: $239-423$.

17. Chou CHH, Tourtellotte WW, Hicks JT, Sato H, Boone EJ, Potvin AR. Failure to detect antibodies to myelin basic protein or peptic fragments of myelin basic protein in CSF of patients with MS. Neurology 1983; 33: 24-28.

18. Hunter WM, Greenwood FC. Preparation of $I^{131}$ human growth hormone of high specific activity. Nature 1962; 195: 495-496.

19. Schumacher GA, Beebe G, Kiebler RE et al. Problems of experimental trials of therapy in multiple sclerosis. Ann NY Acad Sci 1965; 122: 552-568.

20. Panitch HS, Hooper CJ, Johnson KP. CSF antibody to myelin basic protein. Measurement in patients with multiple sclerosis and subacute sclerosing panencephalitis. Arch Neurol 1980; 37: 206-209.

21. Ruutianen J, Arnadottir T, Molnar $G$ et al. Myelin basic protein antibodies in the serum and CSF of multiple sclerosis and subacute sclerosing panencephalitis. (1981). Acta Neurol Scand 1981; 64: 196-206.

22. Wajgt A, Gorny M. Antibodies to myelin basic protein and to myelin-associated glycoprotein in multiple sclerosis. Evidence of intrathecal production of antibodies. Acta Neurol Scand 1983; 68: 337-343.

23. Abramsky O, Lisak RP, Silberberg DH, Pleasure DE. Antibodies to oligodendria in patients with multiple sclerosis. N Eng J Med 1977; 297: 1207-1211.

24. Gorny MK, Wroblewska Z, Pleasure D et al. CSF antibodies to myelin basic protein and oligodendrocytes in multiple sclerosis and other neurological diseases. Acta Neurol Scand 1983; 67: 338-347.

25. Adams JM, Imagawa DT. Measles antibodies in multiple sclerosis. Proc Soc Exp Biol Med III 1962; 562-566.

26. Rorby E, Link H, Alsson JE et al. Comparison of antibodies against different viruses in cerebrospinal fluid and serum samples from patients with multiple sclerosis. Infect Immunity 1974; 10:688-694

27. Baird LG, Tachovsky TC, Sandberg-Wolheim MM et al. Identification of a unique idiotype in cerebrospinal fluid and serum of a patient with multiple sclerosis. J Immunol 1980; 124: 2324-2328.

28. Nagelkerken LM, Aalberse NC, Van Waebeck HK, Out TA. Preparation of antisera directed against the idiotype(s) of $\operatorname{IgG}$ from the cerebrospinal fluid of patients with multiple sclerosis. J Immunol $1980 ; 125: 384-389$. 